\title{
Compression Deformation Behavior of AZ81 Magnesium Alloy at Elevated Temperatures
}

\author{
Xiaoping Luo, Shue Dang, and Li Kang \\ School of Materials Science and Engineering, Shanxi Magnesium and Magnesium Alloy Engineering Technology Research Center, \\ Taiyuan University of Science and Technology, Taiyuan 030024, China
}

Correspondence should be addressed to Shue Dang; lxpsyx@tom.com

Received 23 January 2014; Accepted 9 May 2014; Published 29 May 2014

Academic Editor: Gang Liu

Copyright (c) 2014 Xiaoping Luo et al. This is an open access article distributed under the Creative Commons Attribution License, which permits unrestricted use, distribution, and reproduction in any medium, provided the original work is properly cited.

The hot deformation behavior of an AZ81 magnesium alloy was investigated by hot compressive testing on a Gleeble-1500 thermal mechanical simulator in the temperature range from 200 to $400^{\circ} \mathrm{C}$ and in the strain rate range of $0.001-5 \mathrm{~s}^{-1}$. The relationships among flow stress, strain rate, and deformation temperature were analyzed, and the deformation activation energy and stress exponent were calculated. The microstructure evolution of the AZ81 magnesium alloy under high deformation was examined. The results indicated that the maximum value of the flow stress increased with the decrease of deformation temperature and the increase of strain rate. When the deformation temperature is constant, the flow stress of the AZ81 magnesium alloy increases with the increase of strain rate, which can be demonstrated by a Zener-Hollomon parameter in a hyperbolic-sine-type equation with a hot compression deformation activation energy of $176.01 \mathrm{KJ} / \mathrm{mol}$ and basic hot deformation material factors $A, n$, and $a$ in the analytical expression of the AZ81 magnesium alloy flow stress of $3.21227 \times 10^{14} \mathrm{~s}^{-1}, 7.85$, and $0.00866 \mathrm{MPa}$, respectively.

\section{Introduction}

Magnesium alloy has many superior characteristics, such as low density, high strength/weight ratio, high specific stiffness, good heat and electrical conductivity, excellent electromagnetic shielding, good damping, and easy recycling. For those, it is viewed as "one of the most promising structural engineering materials of the 21st century" [1-3]. At the same time, with the degradation of the environment and the shortage of energy for the requirement of energy conservation and environmental protection, magnesium alloys should be thought of highly by automobile manufacturers because it has been the first choice of weight reduction $[4,5]$.

Due to the balanced mechanical performance of $\mathrm{Mg}$ $\mathrm{Al}-\mathrm{Zn}$ (AZ series) magnesium alloys, they are widely used in the field of industrial production, as well as in the aerospace, automobile, and electronic industries. However, it is true that high-performance magnesium alloys are limited because of their dense-hexagonal structure, low slip system, and inferior cold plastic processing ability. Hence, it is of considerable significance to study flow stress behaviors of magnesium alloys. AZ31-AZ81 magnesium alloys belong to wrought magnesium alloys while AZ91 belongs to casting magnesium alloy in commercial AZ series magnesium alloys. Most researchers who are studying the deformation behavior are focused on two kinds of alloys including AZ31 [6-8] and AZ91 [9-11] magnesium alloys.

However, the AZ81 wrought magnesium alloy, holding plastic weak and medium strength, is short of systematical research on the behavior of the high-temperature large deformation process and the hot working processing parameter. To examine the hot deformation behavior, the flow stress of materials at elevated temperature is one of the most indispensable pieces of information. During the hot deformation process, the flow stress behavior is usually characterized by certain factors such as strain rate, strain, deformation temperature, and deformation activation energy $[12,13]$. Equations expressing the flow stress as a function of strain, strain rate, and temperature are useful to numerically analyze the hot deformation process and are most frequently used in engineering practice. For this reason, it is very important and necessary to investigate the behavior of the plastic deformation of the AZ81 magnesium alloy at elevated temperature to provide suitable plastic processing 


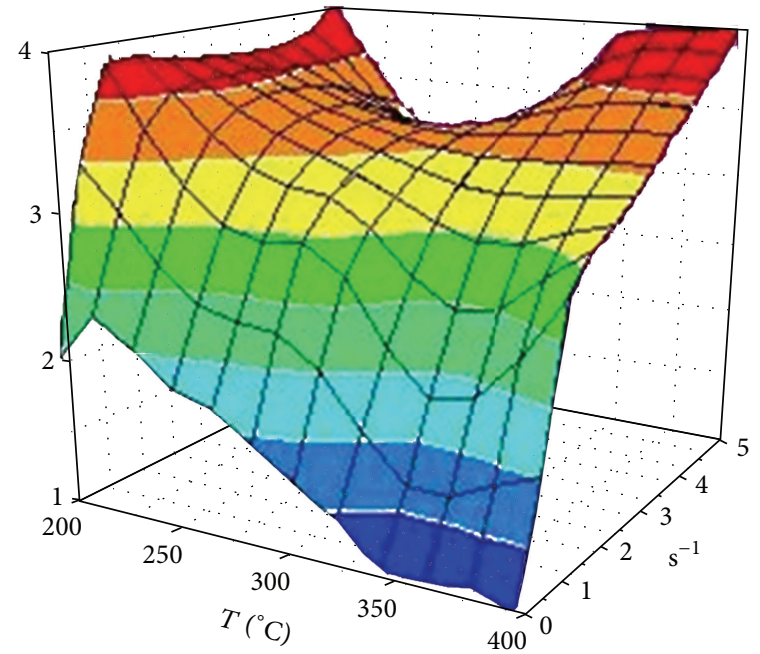

FIgURE 1: Relationship among macroscopic morphology, deformation temperature, and strain rate.

experimental data for advancing research into magnesium alloys.

\section{Materials and Methods}

The chemical composition of the experimental materials is shown in Table 1. A magnesium ingot was first made by casting and then by processing with homogenizing treatment at $400^{\circ} \mathrm{C}$ for $12 \mathrm{~h}$. The sample can be attained after the ingot was axially processed in a cylinder of $\phi 8 \mathrm{~mm} \times 12 \mathrm{~mm}$. The obtained samples were compressed on a Gleeble-1500 thermal mechanical simulator under temperature ranging from $200^{\circ} \mathrm{C}$ to $400^{\circ} \mathrm{C}$, at various stress rates ranging from 0.001 to $1 \mathrm{~s}^{-1}$, in which lubricant was added at both ends of the sample for less friction between the sample and the indenter. After the compression tests, the samples were held for 3 minutes under a deformation temperature and water-quenched within $0.5 \mathrm{~s}$ after testing to retain the developed microstructure. The microstructures of the alloy were observed through an optical microscope.

\section{Results and Discussion}

3.1. Macroscopic Morphology and Microstructure Evolution during Compression Deformation. The three-dimensional relationship of the macroscopic morphology, deformation temperature, and strain rate is shown in Figure 1. The $z$ axis represents the breakage of the sample. Cracks in the sample after compression, herein denoted as " 1 ," “2," “ 3 ," and " 4 " for increasing severity in cracking, were selected for macroscopic morphology examination along the $Z$-axis. It can be seen that the AZ81 magnesium alloy samples did not fail after compression at $200^{\circ} \mathrm{C}$ to $400^{\circ} \mathrm{C}$ and $0.001-0.1 \mathrm{~s}^{-1}$, but tiny cracks are evident at $200^{\circ} \mathrm{C}$, while more local cracking occurs when the strain rate increased at $200^{\circ} \mathrm{C}$ to $300^{\circ} \mathrm{C}$ and $\geq 1 \mathrm{~s}^{-1}$. However, no noticeable cracking occurred at $300^{\circ} \mathrm{C}$ to $400^{\circ} \mathrm{C}$ and $\geq 1 \mathrm{~s}^{-1}$, but serious cracking was found in the test specimen $\mathrm{c}$ at $400^{\circ} \mathrm{C}$ and $5 \mathrm{~s}^{-1}$.

The microstructure evolution of the AZ81 magnesium alloy deformed to high strains at $300^{\circ} \mathrm{C}$ and $0.01 \mathrm{~s}^{-1}$ is presented in Figure 2. It should be seen that the volume fraction of the recrystallized grains increased with increasing strain, but, at $\varepsilon=50 \%$ of the deformation (Figure $2(\mathrm{a})$ ), the grain size is elongated but does not show a distinct change. With a higher deformation value $(\varepsilon=75 \%$, Figure $2(\mathrm{~b}))$, a few original grains remain with an appropriately oblate rhomboid shape, and the area of DRX becomes considerable. With the deformation $\varepsilon=90 \%$ (Figure $2(\mathrm{c})$ ), the grain boundary is not obvious, making it impossible to separate the grains. Hence, the stress-strain relations are no longer suitable under severe deformation conditions.

Figure 3 shows the microstructures of the AZ81 magnesium alloy when compressed at different temperatures with $\varepsilon=60 \%$ and $0.1 \mathrm{~s}^{-1}$. It can be seen that, at the temperature range from 200 to $400^{\circ} \mathrm{C}$, the original grains are prolonged. The DRX occurs but the volume fraction of the recrystallized grains is very small and they are mainly distributed inhomogeneously along the original grain boundaries. The DRX proceeds more adequately with increasing temperature. When the temperature rises to $400^{\circ} \mathrm{C}$, the DRX is complete and the grains are evenly distributed over the sample.

\subsection{True Stress-Strain Behavior of AZ81 Magnesium Alloy.} The shape of the stress-strain curves is considered to contain some information related to the mechanisms of hot deformation, as illustrated in Figure 4, which is composed of four stages as follows: (I) work hardening stage: the hardening rate is higher than the softening rate and the stress rises steeply under microstrain deformation and then increases at a decreased rate; (II) stable stage: equilibrium is obtained between the dislocation generation and the annihilation rate, corresponding to a short stable stage; (III) softening stage: the dislocations are annihilated in large numbers through the migration of a high angle boundary, and the stress drops steeply; (IV) steady stage: the stress becomes steady when a new balance between softening and hardening is obtained. The flow stress is affected by many factors, but, for a given material and deformation mode, the shape of the flow curve is primarily affected by the strain rate and temperature.

The true stress-strain behaviors of the AZ81 magnesium alloy at suitable strain rates and deformation temperatures are shown in Figure 5. It can be seen that the flow stresses of the general and typical characteristics of the AZ81 magnesium alloy in the experiments increase to their maximum values at the initial stage of deformation and then decrease to attain a steady state. When the strain is less than the strain corresponding to the peak stress, the strain hardening plays the main role. As the true strain continues increasing, the strain softening effect is larger than the strain-hardening effect owing to dynamic recrystallization, and then the flow stress decreases. So it can be concluded that DRX occurs easily when the AZ81 magnesium alloy is deformed at an elevated temperature. 

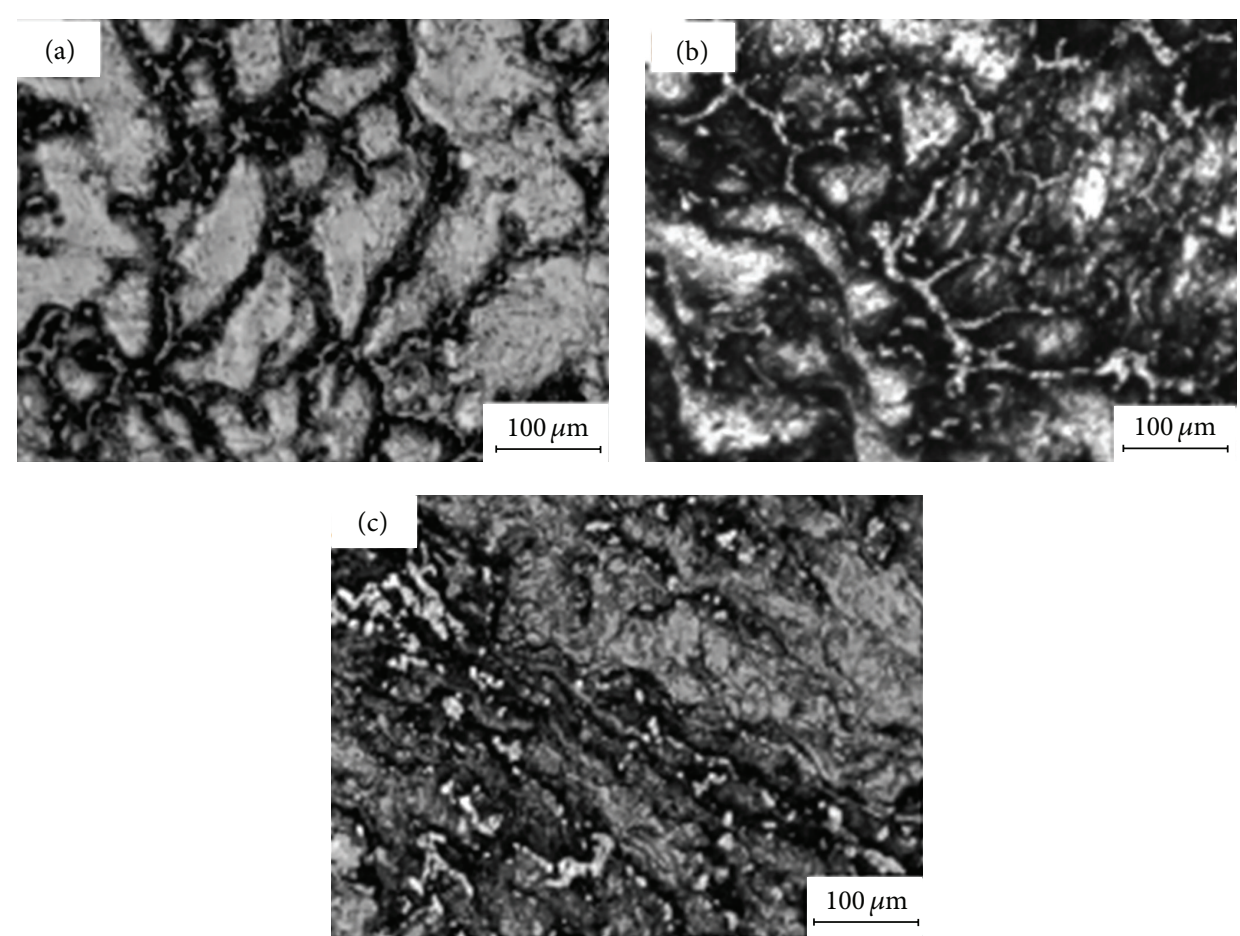

FIgURE 2: Microstructure of AZ81 magnesium alloy at $300^{\circ}$ C. $\varepsilon=(a) 50 \%$, (b) $75 \%$, and (c) $90 \%$.
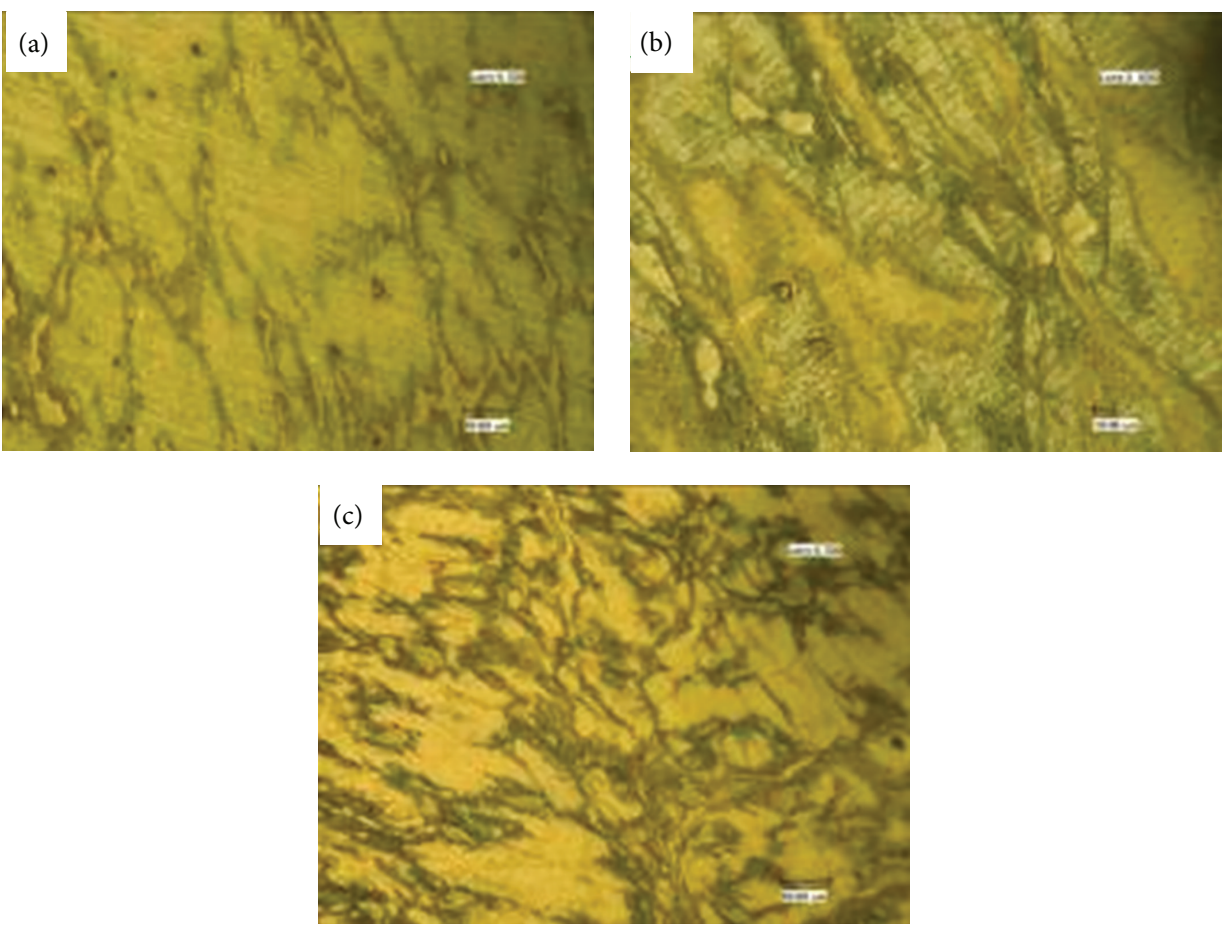

Figure 3: Microstructure evolution with deformation of $60 \%$ and $0.1 \mathrm{~s}^{-1}$ : (a) $\mathrm{T}=200^{\circ} \mathrm{C}$; (b) $\mathrm{T}=300^{\circ} \mathrm{C}$; (c) $\mathrm{T}=400^{\circ} \mathrm{C}$.

TABLE 1: Chemical composition of AZ81 magnesium alloy.

\begin{tabular}{lccccccccc}
\hline Element & $\mathrm{Al}$ & $\mathrm{Zn}$ & $\mathrm{Mn}$ & $\mathrm{Si}$ & $\mathrm{Fe}$ & $\mathrm{Cu}$ & $\mathrm{Ni}$ & $\mathrm{Be}$ & $\mathrm{Mg}$ \\
\hline Mass $\%$ & 8.85 & 0.626 & 0.278 & 0.033 & 0.0086 & 0.0025 & $<0.0005$ & 0.0018 & Trace \\
\hline
\end{tabular}




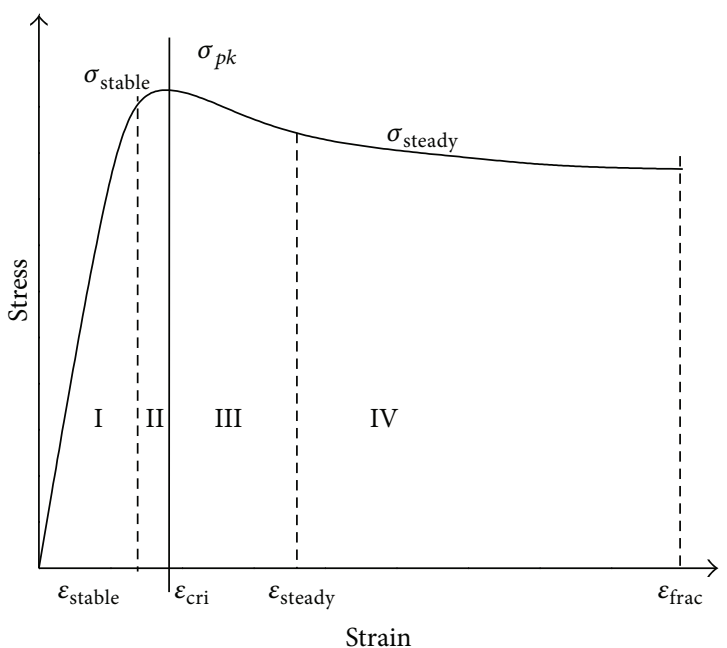

Figure 4: Typical stress-strain curve at the elevated temperature.

It also can be seen from Figure 5 that when the deformation temperature is considered, the peak value increases with increasing deformation rate. The major cause of this is the increasing flow stress because the DRX cannot be accompanied entirely for higher rates of strain. When strain rate is considered, the peak value of the flow stress decreases gradually along with the increasing temperature as it increases along with the decline of the strain rate and true strain value, which both become small in the stable-deformation stage. The characteristics above are caused by the low resistance of deformation, which is led by the enlargement of the atomic moving ability and enforcement of the thermoactivation effect at the elevated temperature. In addition, dynamic recrystallization occurs more easily in this condition, which in turn results in an advancing of the peak stress along with the increase of temperature.

3.3. Relationship between the Deformation Parameters and the Deformation Activation Energy. It is clear that there is a relationship among the flow stress, strain rate, and deformation temperature of the AZ81 magnesium alloy. Therefore, it is necessary to make it clear to understand the plastic deformation behavior of the alloy at high temperature to pave the way for extrusion processing.

Usually, the following constructive equations are used to describe the relationship of the stable flow stress of materials at elevated temperature with different strain rates:

$$
\begin{gathered}
\dot{\varepsilon}=A_{1} \sigma^{n_{1}}, \quad \alpha \sigma<0.8, \\
\dot{\varepsilon}=A_{2} \exp (\beta \sigma), \quad \alpha \sigma>1.2, \\
\dot{\varepsilon}=A[\sinh (\alpha \sigma)]^{n} \exp \left(\frac{-Q}{R T}\right), \quad \text { all, }
\end{gathered}
$$

where $A, A_{1}, A_{2}, a, n_{1}$, and $\beta$ are all constants, $a=\beta / n_{1} ; \dot{\varepsilon}$ is the strain rate; $\sigma$ is the flow stress; $n$ is the stress index; $Q$ is the deformation activation energy, which shows how easily the material is hot-deformed; $R$ is the molar gas constant; $T$ is the absolute deformation temperature. Equations (1) and (2) are usually given at different stress levels, respectively. Equation (3) covers all stress ranges.

It is a hyperbolic sine form of the Arrhenius function including deformation activation energy and deformation temperature, which determine the characteristics of stable hot deformation behavior. Much study has been conducted to prove that the hyperbolic function can be applied to integral deformation behavior as well as to calculate the deformation activation energy $Q$ of magnesium alloys. Takuda et al. [14, 15] proposed an index relationship method to express the proof stress of magnesium-based alloys AZ31 and AZ91 in hot working processes. Barnett [16] proposed a hyperbolic function to express the stress of the AZ31 magnesium alloy in hot working processes. Considering the experimental conditions, the logarithmic transformations for (1)-(3) are

$$
\begin{gathered}
\ln \dot{\varepsilon}=\ln A_{1}+n_{1} \ln \sigma, \\
\ln \dot{\varepsilon}=\ln A_{2}+(\beta \sigma), \\
\ln \dot{\varepsilon}+\frac{Q}{R T}=\ln A+n \ln [\sinh (\alpha \sigma)] .
\end{gathered}
$$

After partial derivatives are taken from both sides, (4)-(6) are, respectively, transformed into

$$
\begin{gathered}
n_{1}=\frac{\partial \ln \dot{\varepsilon}}{\partial \ln \sigma}, \\
\beta=\frac{\partial \ln \dot{\varepsilon}}{\partial \sigma}, \\
Q=R\left[\frac{\partial \ln \dot{\varepsilon}}{\partial \ln [\sinh (\alpha \sigma)]}\right]_{T} *\left[\frac{\partial \ln [\sinh (\alpha \sigma)]}{\partial(1 / T)}\right]_{\dot{\varepsilon}}
\end{gathered}
$$

where

$$
\begin{aligned}
& n=\frac{\partial \ln \dot{\varepsilon}}{\partial \ln [\sinh (\alpha \sigma)]}, \\
& s=\frac{\partial \ln [\sinh (\alpha \sigma)]}{\partial(1 / T)} .
\end{aligned}
$$

According to (4) and (5), from the linear relationship in $\ln \dot{\varepsilon}-\sigma$ and $\ln \dot{\varepsilon}-\ln \sigma$, shown in Figure 6, it can be found that the values of $n_{1}=15.2$ and $\beta=0.13$, respectively, and $a=0.00866$ can be calculated after optimal processing. Figure 7 shows good linearity and a parallel variation of the peak flow stress with strain rate, plotted as a logarithmic slope of 7.85. The apparent activation energy for the deformation can be obtained from the Arrhenius plots of $1 / T$, as shown in Figure 8, in which the slope of line $s$ is 2.7. Hence, $Q=$ Rns $=8.31 \times 7.85 \times 2.7=176.01 \mathrm{KJ} / \mathrm{mol}$; that is, the hot deformation activation energy of the AZ81 magnesium alloy derived from experimental data is higher than that of the AZ41 magnesium alloy [17] and lower than that of the AZ91D magnesium alloy [18]. The value of $Q$ higher in different alloy may be associated with the addition of $\mathrm{Al}$ atoms, which can play a role in causing dislocation slipping to occur during the hot deformation. This will increase the energy for dislocation slipping and climbing and, consequently, increase the energy for dynamic recrystallization. 

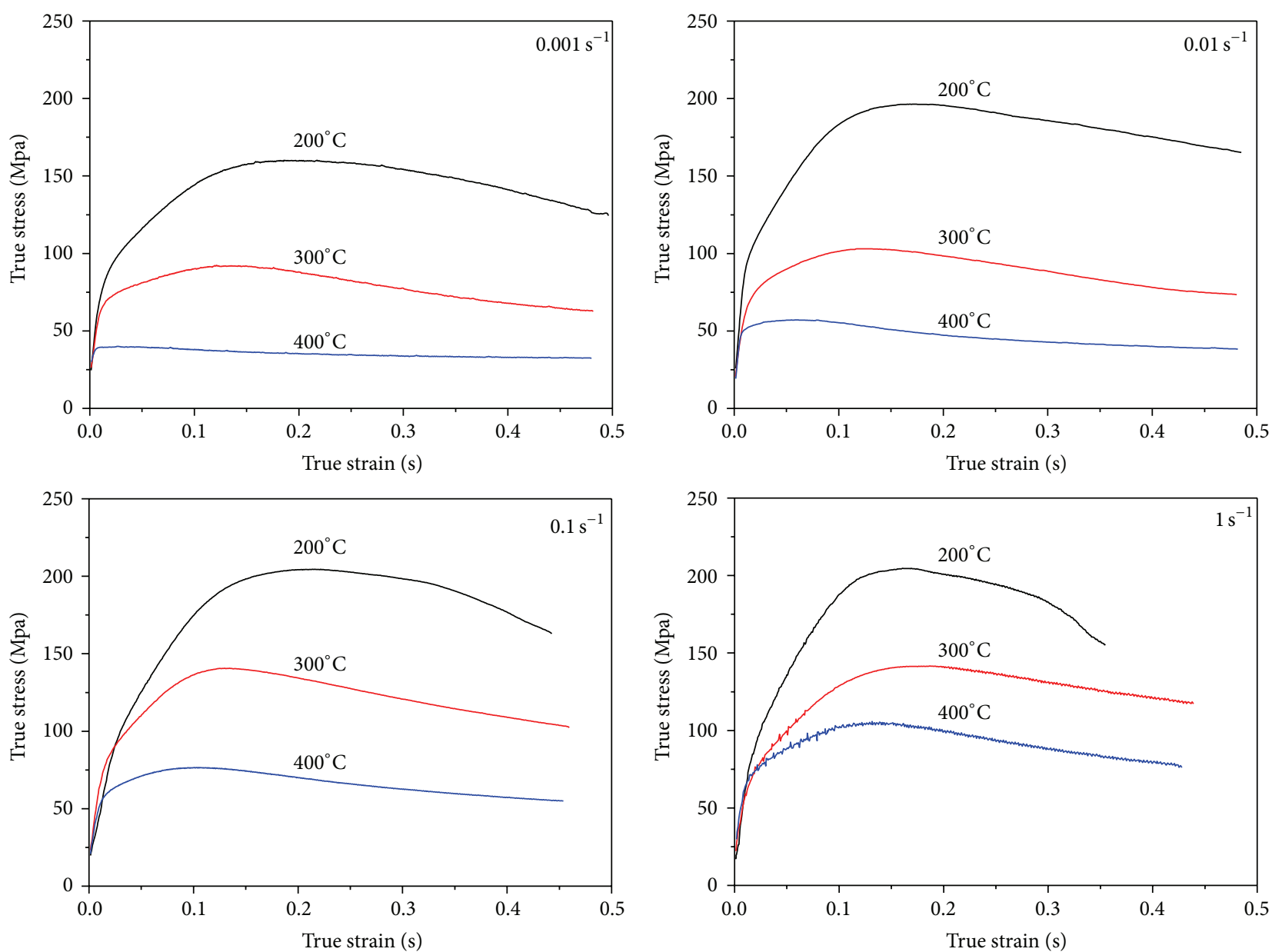

FIGURE 5: True stress-true strain curves of AZ81 magnesium alloy during hot compression deformation.

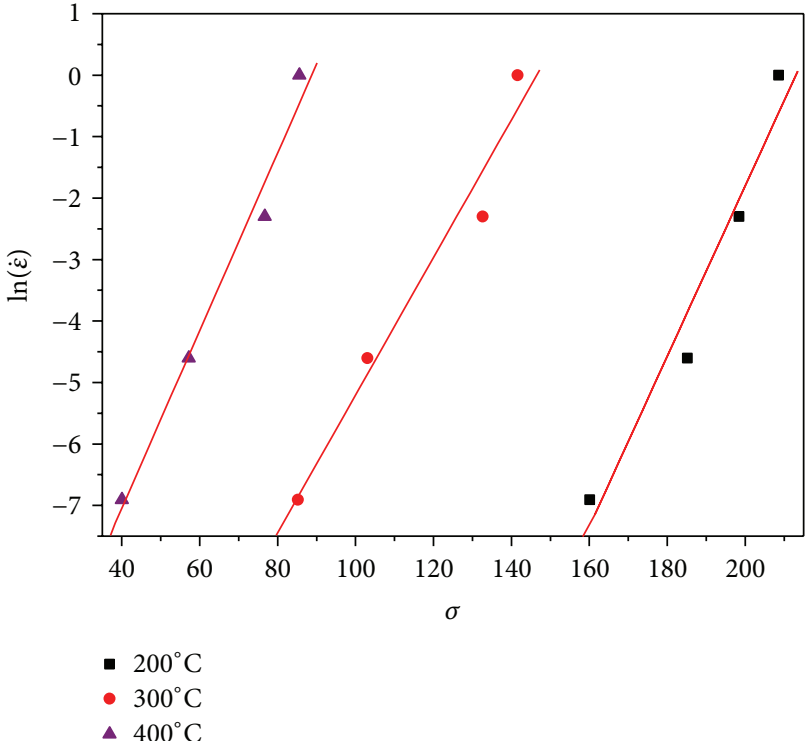

(a)

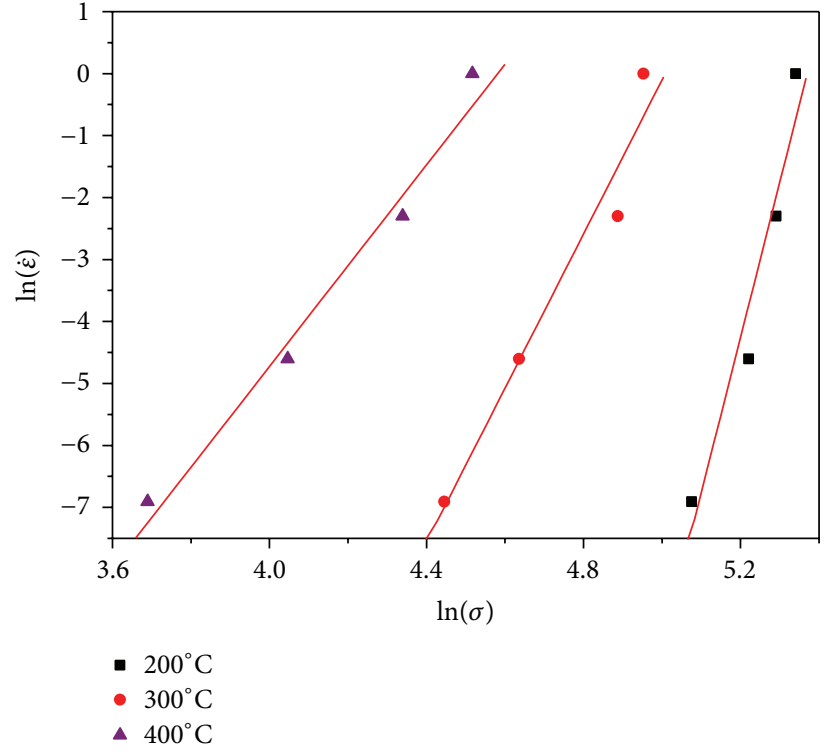

(b)

FIGURE 6: Relationship between strain rate and peak stress of AZ81 magnesium alloy: (a) $\ln \dot{\varepsilon}-\ln \sigma$; (b) $\ln \dot{\varepsilon}-\sigma$. 


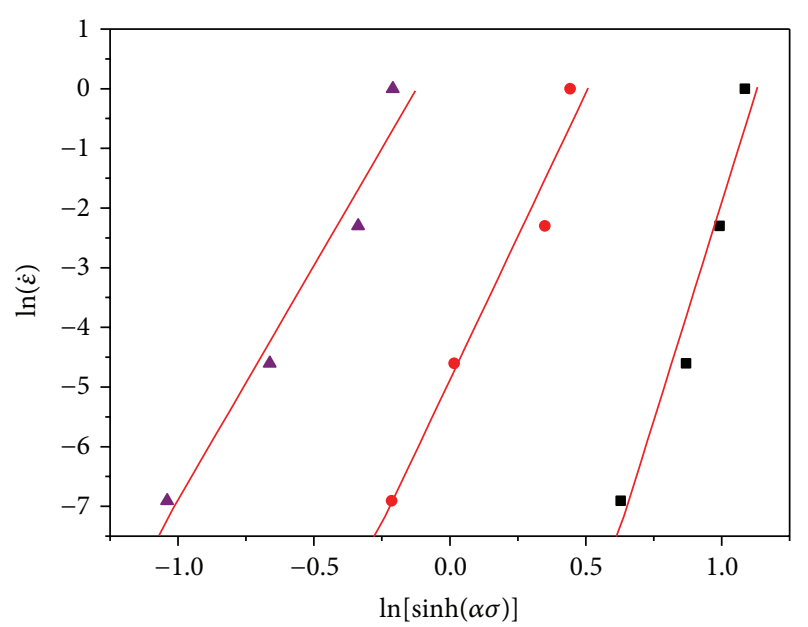

- $200^{\circ} \mathrm{C}$

- $300^{\circ} \mathrm{C}$

- $400^{\circ} \mathrm{C}$

FIGURE 7: Relationship between strain rate and flow stress for AZ81 magnesium alloy.

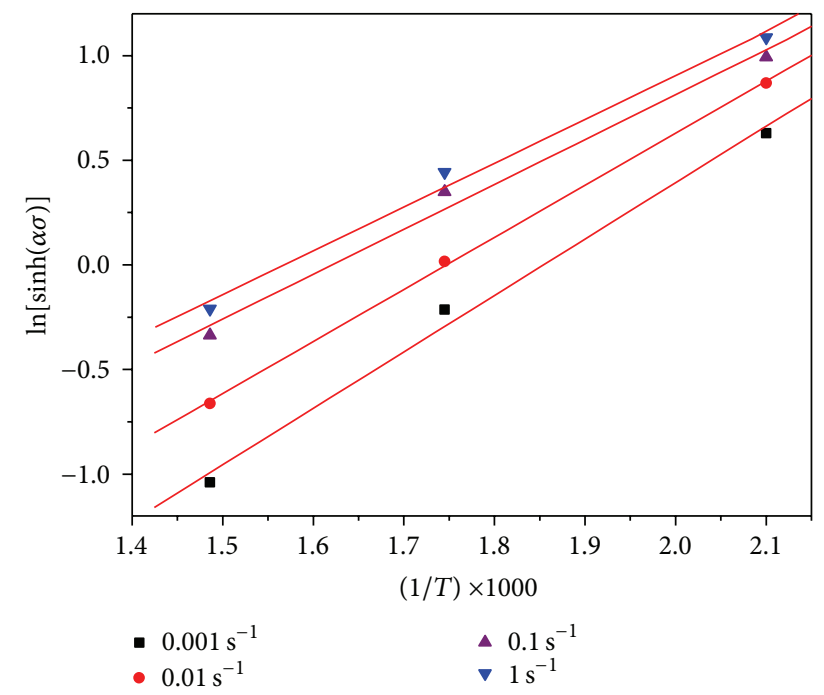

FIGURE 8: Relationship between flow stress and temperature of AZ81 magnesium alloy.

The hot deformation conditions are usually expressed in terms of temperature, compensated strain rate $(Z)$, and the Zener-Hollomon parameter:

$$
Z=\dot{\varepsilon} \exp \left(\frac{Q}{R T}\right) .
$$

The substitution of (9) into (3) results in

$$
Z=\dot{\varepsilon} \exp \left(\frac{Q}{R T}\right)=A[\sinh (\alpha \sigma)]^{n} .
$$

After logarithmic processing of (10), the equation becomes

$$
\ln Z=\ln A+n \ln [\sinh (\alpha \sigma)]=\ln \dot{\varepsilon}+\frac{Q}{R T} .
$$

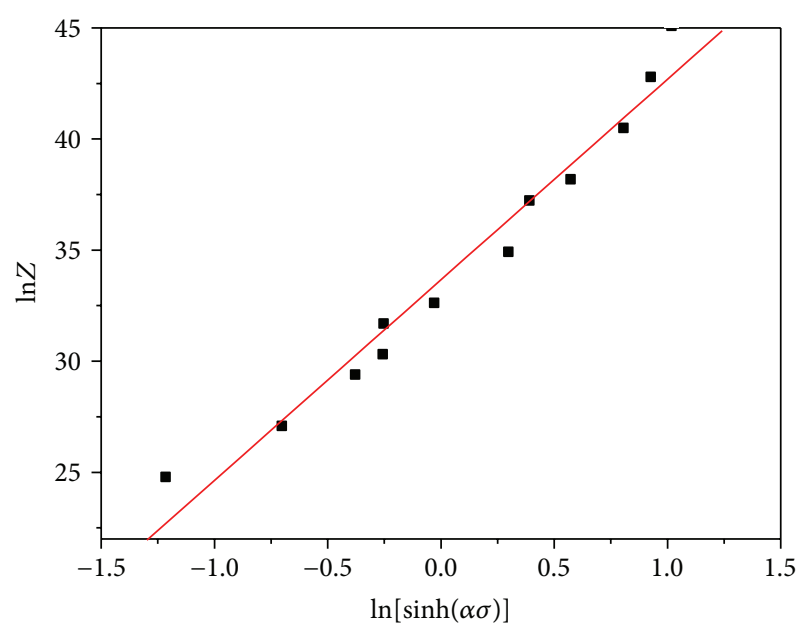

FIGURE 9: Relationship between parameter $Z$ and flow stress.

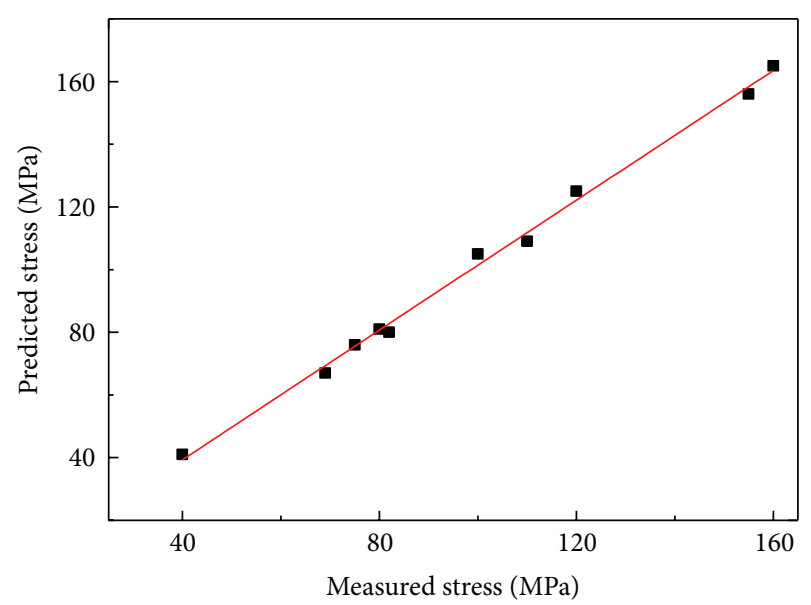

FIGURE 10: Comparison of the predicted and measured flow stress of AZ81 magnesium alloy at $300^{\circ} \mathrm{C}$ and $0.001 \mathrm{~s}^{-1}$.

Figure 9 shows the linear relationship between $\ln Z$ and $\ln [\sinh (\alpha \sigma)]$ with a correlation factor of 0.98258 , which demonstrates that the hyperbolic sine function is appropriately applied to the hot deformation behavior of AZ81 magnesium alloy. The value of $A$ is derived to be $A=$ $3.21227 \times 10^{14}$. The flow stress function of hot deformation of the AZ81 magnesium alloy can be obtained after the substitution of $n, \alpha, A$, and $Q$. The formula of flow stress is therefore determined to be

$$
\dot{\varepsilon}=3.21227 \times 10^{14}[\sinh (0.00866 \sigma)]^{7.85} \exp \left(\frac{-176010}{R T}\right) .
$$

Figure 10 shows the experimentally derived stress and the calculated stress with a good fit together, indicating that this flow stress formula is correct. And this result might provide a more scientific basis for the plastic forming of the AZ81 magnesium alloy. 


\section{Conclusions}

The conclusions are as follows.

(1) The high-temperature deformation behaviors of AZ81 magnesium alloy are affected considerably by the deformation temperature and deformation rate. The flow stress increases with the increase of stress rate under a fixed temperature and decreases with the increase of deformation temperature under a fixed stress rate.

(2) Through the analysis of the macroscopic morphology of the AZ81 magnesium alloy corresponding to matrix cracking and microstructure evolution during compression deformation, the processing domain lies in the range from 200 to $400^{\circ} \mathrm{C}$ and at a strain rate in the range of $0.01-1 \mathrm{~s}^{-1}$. Hence the domain of the temperature and strain rates are constrained.

(3) Through the analysis and calculation of the elevatedtemperature deformation behaviors of the AZ81 magnesium alloy, some basic material factors can be established and the values of $A, n$, and $a$ in the analytical expression of flow stress are fixed to be $3.21227 \times$ $10^{14} \mathrm{~s}^{-1}, 7.85$, and $0.00866 \mathrm{MPa}$, respectively. The hot deformation activation energy $(Q)$ is $176.01 \mathrm{KJ} / \mathrm{mol}$.

\section{Conflict of Interests}

The authors declare that there is no conflict of interests regarding the publication of this paper.

\section{Acknowledgments}

The study was financially supported by both the Nature Science Foundation of Shanxi Province, China (no. 20120110225 ), and the Doctoral Foundation of Taiyuan University of Science and Technology (no. 20132019).

\section{References}

[1] Z.-H. Chen, W.-J. Xia, and H.-G. Yan, "Wrought magnesium alloy," in ECT, vol. 5, pp. 3-6, Chemical Industry Press, Beijing, China, 2005, (Chinese).

[2] Z.-S. Ji, "Research process and new technology of magnesium alloy in Japan," Chinese Journal of Nonferrous Metals, vol. 14, no. 12, pp. 1977-1984, 2004.

[3] Q. Guo, H.-G. Yan, Z.-H. Chen, and H. Zhang, "Study on the flow stress of hot compressions of Mg-AI-Zn alloy," Journal of Hunan University Natural Sciences, vol. 33, no. 3, pp. 75-79, 2006 (Chinese).

[4] Z.-H. DU, X.-H. Zhang, X.-Y. Fang, X.-J. Zhang, Y.-L. Chen, and Y.-W. Zhang, "Hot compression deformation behavior of MB26 magnesium alloy," Journal of Tram Nonferrous MetSoe China, vol. 17, no. 2, pp. 400-404, 2007.

[5] T. Mukai, "Grain refinement of commercial magnesium alloys for high-strain-rate-superplastic forming," Journal of Material Science Forum, vol. 350-351, pp. 159-170, 2000.

[6] Y. Li, Y. Chen, H. Cui, J. Ding, L. Zuo, and J. Zhang, "Hot deformation behavior of a spray-deposited AZ31 magnesium alloy," Rare Metals, vol. 28, no. 1, pp. 91-97, 2009.
[7] Q. Dai, D. Zhang, and X. Chen, "On the anisotropic deformation of AZ31 Mg alloy under compression," Materials and Design, vol. 32, no. 10, pp. 5004-5009, 2011.

[8] L. Juan Hu, Y. H. Peng, D. Yong Li, and S. Rui Zhang, "Influence of dynamic recrystallization on tensile properties of AZ31B magnesium alloy sheet," Materials and Manufacturing Processes, vol. 25, no. 8, pp. 880-887, 2010.

[9] X.-H. Zhang, J.-F. Jiang, and S.-J. Luo, "Compression deformation behavior of AZ91D magnesium alloy at elevated temperature," Chinese Journal of Nonferrous Metals, vol. 19, no. 10, pp. 1720-1725, 2009 (Chinese).

[10] S.-B. Li, Y.-Q. Wang, M.-Y. Zheng, and K. Wu, "Dynamic recrystallization of AZ91 magnesium alloy during compression deformation at elevated temperature," Transactions of Nonferrous Metals Society of China, vol. 14, no. 2, pp. 306-310, 2004.

[11] Z. Wang, X. Liu, and J. Xie, "Constitutive relationship of hot deformation of AZ91 magnesium alloy," Acta Metallurgica Sinica, vol. 44, no. 11, pp. 1378-1383, 2008 (Chinese).

[12] A. G. Beer and M. R. Barnett, "Microstructural development during hot working of Mg-3Al-1Zn," Metallurgical and Materials Transactions A, vol. 38, pp. 1856-1867, 2007.

[13] S. Wang, L. Song, S. Kang, J. Cho, and Y. Wang, "Deformation behavior and microstructure evolution of wrought magnesium alloys," Chinese Journal of Mechanical Engineering, vol. 26, no. 3, pp. 437-447, 2013.

[14] H. Takuda, H. Fujimoto, and N. Hatta, "Modelling on flow stress of Mg-Al-Zn alloys at elevated temperatures," Journal of Materials Processing Technology, vol. 80-81, pp. 513-516, 1998.

[15] A. Galiyev, R. Kaibyshev, and G. Gottstein, "Correlation of plastic deformation and dynamic recrystallization in magnesium alloy ZK60," Acta Materialia, vol. 49, no. 7, pp. 1199-1207, 2001.

[16] M. R. Barnett, "Influence of deformation conditions and texture on the high temperature flow stress of magnesium AZ31," Journal of Light Metals, vol. 1, no. 3, pp. 167-177, 2001.

[17] S. Wang, M. Wang, R. Ma, Y. Wang, and Y. Wang, "Microstructure and hot compression behavior of twin-roll-casting AZ41M magnesium alloy," Rare Metals, vol. 29, no. 4, pp. 396-400, 2010.

[18] Y. Xue, Z.-M. Zhang, L.-H. Lang, and H.-J. Li, "High temperature compression deformation behaviors of AZ91D alloy," Journal of Forging \& Stamping Technology, vol. 34, no. 1, pp. 135138, 2009. 

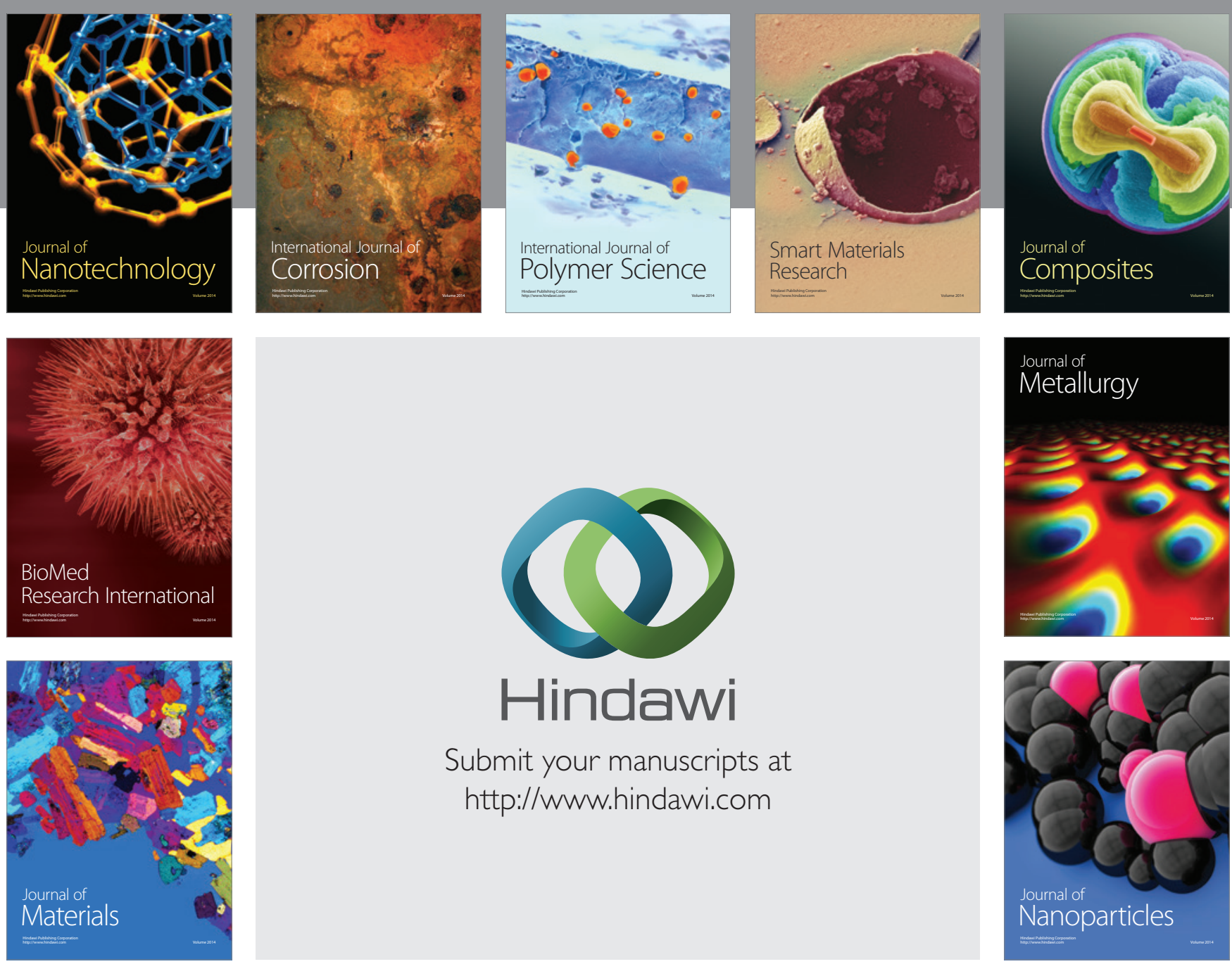

Submit your manuscripts at http://www.hindawi.com
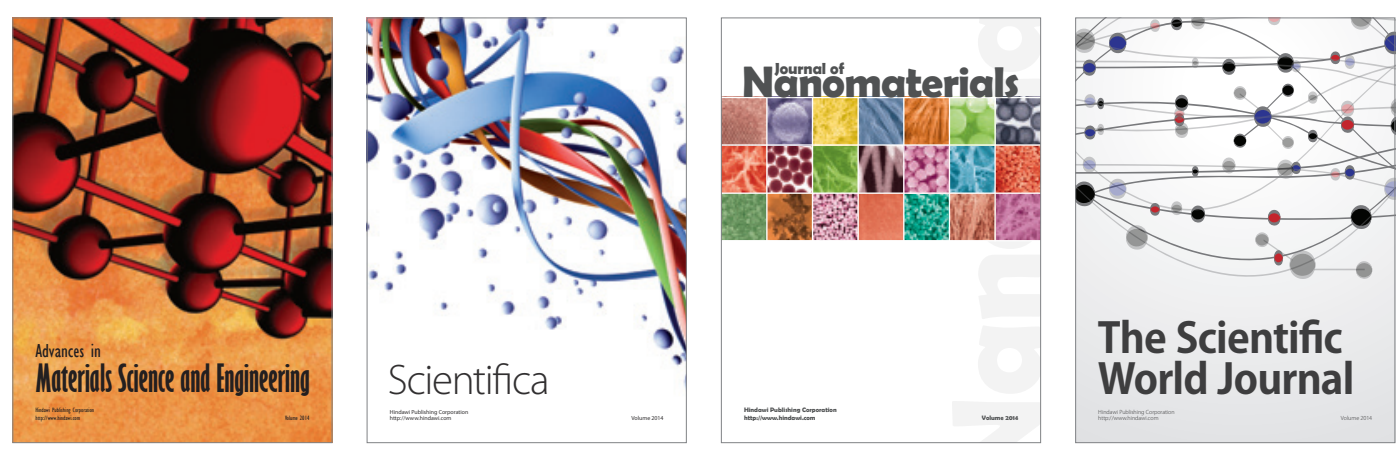

\section{The Scientific World Journal}
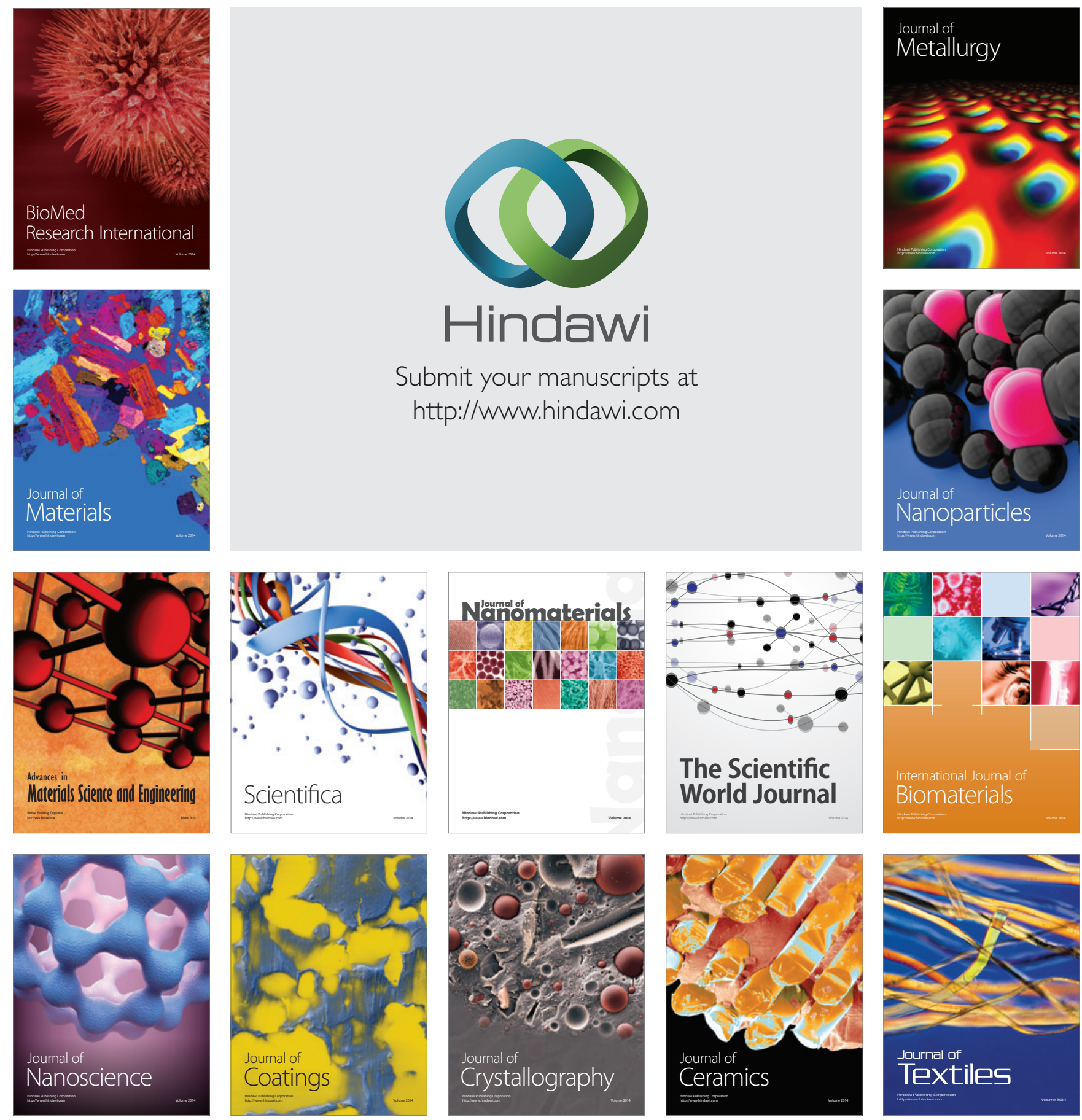